\title{
Anterior Screw Fixation in Type II Odontoid Fractures: Keys for Better Outcome in Early Experience in Developing Countries
}

\author{
Ahmed El Fiki*, Hisham El Shitany \\ Department of Neurosurgery, Faculty of Medicine, Cairo University, Cairo, Egypt \\ Email: *asfiki@yahoo.com
}

How to cite this paper: El Fiki, A. and El Shitany, H. (2018) Anterior Screw Fixation in Type II Odontoid Fractures: Keys for Better Outcome in Early Experience in Developing Countries. Open Journal of Modern Neurosurgery, 8, 360-369.

https://doi.org/10.4236/ojmn.2018.84031

Received: June 13, 2018

Accepted: August 13, 2018

Published: August 16, 2018

Copyright (c) 2018 by authors and Scientific Research Publishing Inc. This work is licensed under the Creative Commons Attribution International License (CC BY 4.0).

http://creativecommons.org/licenses/by/4.0/

\begin{abstract}
Introduction: Representing up to $15 \%$ of cervical injuries, odontoid type II fractures may cause spinal cord compression through atlanto-axial instability. Anterior screw fixation provides direct fracture site stability, high fusion rate and most importantly keeping cervical spine move free. We will highlight success keys in early experience for better outcome. Methods: We operated ten cases with traumatic type II odontoid fractures in neurotrauma unit, Cairo University hospitals from March 2015 till June 2017. Six males and four females were included. Preoperative MRI and dynamic CT were among the assessment criteria. Uni-planner fluoroscopy was used. Results: No post-operative deficit appeared. One screw was inserted in all cases. Immediate and 6 weeks later CT cervical spine showed stable reduced fracture site. Conclusions: Anterior odontoid screw fixation done with prior good selection of the patient and fracture shape is an effective motion preserving surgical option for type II odontoid fractures. Limited resources shouldn't prevent starting experience especially in developing countries, but larger studies are needed.
\end{abstract}

\section{Keywords \\ Odontoid, Screw, Fracture, Outcome}

\section{Introduction}

Odontoid fractures represent from $15 \%-20 \%$ of all cervical vertebrae breaks [1] [2] [3]. Its occurrence increases considerably in aging people to the extent that it is the commonest cervical fracture in $7^{\text {th }}$ decade and the older [4] [5].

The commonest type of odontoid fractures is type II reaching from $65 \%$ to $74 \%$ of all patients [6] [7] [8]. Odontoid type II fractures simulate transverse 
ligament tear in allowing translation of $\mathrm{C}-1$ over $\mathrm{C}-2$, facilitating cervical cord injury and subsequent late, mal and non-union [9] [10] [11].

Bohler, in 1982, performed the first anterior odontoid screw fixation [12]. Indications and surgical techniques have since evolved, and anterior screwing is now, where feasible, the most widely used osteosynthesis technique. It conserves the mobility of the $\mathrm{C} 1-\mathrm{C} 2$ joint, which provides $50 \%$ of cervical spine rotation. It also obviates the need for a posterior approach, which is much more damaging to the muscles, often inducing chronic cervicalgia. There are variants on the technique, some teams using two screws and others crossing the superior odontoid cortical surface.

Currently, anterior screw insertion through odontoid process will provide better anatomical and functional outcome in cases of odontoid type II fractures if transverse ligament is intact [13] [14] [15] [16].

Through this, immediate stabilization of fracture line and preservation of rotatory movement of cervical spine will be maintained [17].

Recent advances in intra-operative imaging including neuronavigation and $\mathrm{O}$-arm can now increase accuracy and lower morbidity of odontoid screw placement [18] [19] [20].

However, limited resources in many centres especially in most of developing countries will make availability of these tools difficult. In current study, we will discuss how to avoid pitfalls that may result from absence of these new tools trying to achieve fixation through free hand technique and build up experience.

\section{Materials and Methods}

Our cohort study where conducted in neurotraumatology unit of Cairo university hospitals from March 2015 to March 2017 over 10 patients (as shown in Table 1).

\section{Inclusion criteria:}

- Acute Traumatic type II (a \& b) odontoid fracture.

- Surgically fit patients.

\section{Exclusion criteria:}

- Disrupted transverse ligament.

- Type IIc odontoid fracture.

- Associated Jefferson's fractures.

- Short neck, emphysematous chest.

- Old fractures (sclerosed edges).

Thorough neurological examinations including associated conditions were reported. Computerized topography (C.T) of cervical spine with reconstruction to evaluate type and shape of odontoid fracture, also not to miss other cervical vertebrae fractures. This was followed by complementary MRI cranio-cervical region to check ligamentous integrity and cervical cord contusion if present. Age, sex, mode of injury, pre- and post-operative motor power were documented.

After confirming the diagnosis radiographically, treatment options were discussed with the patient including further consequences of each modality. We did 
Table 1. Clinical and sociodemographic data of the patients. (M: male; F: female; RTA: road trafiic accident; FFH: fall from a height; Lt: left; Rt: right.)

\begin{tabular}{|c|c|c|c|c|c|}
\hline No & Age/sex & $\begin{array}{l}\text { Mode of } \\
\text { trauma }\end{array}$ & symptoms & $\begin{array}{l}\text { Associated } \\
\text { injuries }\end{array}$ & $\begin{array}{c}\text { Medical } \\
\text { comorbidities }\end{array}$ \\
\hline 1 & $22 / \mathrm{M}$ & RTA & Neck pain & $\begin{array}{l}\text { Lt frontal fissure } \\
\text { fracture }\end{array}$ & None (Figure 1) \\
\hline 2 & $43 / \mathrm{F}$ & RTA & Neck pain & $\begin{array}{l}\text { Lung contusion \& } \\
\text { fracture ribs }\end{array}$ & None \\
\hline 3 & $45 / \mathrm{M}$ & FFH & Neck pain & Fracture Rt clavicle & None (Figure 2) \\
\hline 4 & $34 / \mathrm{M}$ & RTA & $\begin{array}{l}\text { Neck pain, UL } \\
\text { weakness }\end{array}$ & $\begin{array}{l}\text { C3/4 spinal cord } \\
\text { contusion }\end{array}$ & None \\
\hline 5 & $39 / \mathrm{F}$ & RTA & Neck pain & None & None \\
\hline 6 & $52 / \mathrm{M}$ & FFH & Neck pain & None & HTN \\
\hline 7 & $27 / \mathrm{F}$ & RTA & $\begin{array}{l}\text { Neck pain, UL } \\
\text { weakness }\end{array}$ & $\begin{array}{l}\text { Pelvic fracture. } \\
\text { C3-5 Spinal cord } \\
\text { contusion. }\end{array}$ & None \\
\hline 8 & $59 / \mathrm{M}$ & RTA & Neck pain & Skull base fracture & DM, HTN \\
\hline 9 & $23 / \mathrm{F}$ & RTA & Neck pain & None & None \\
\hline 10 & $27 / M$ & FFH & Neck pain & Skull base fracture & None \\
\hline
\end{tabular}

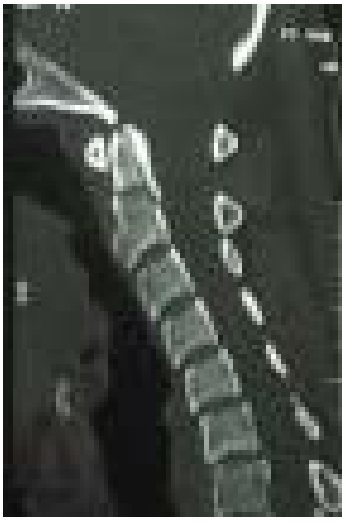

(a)

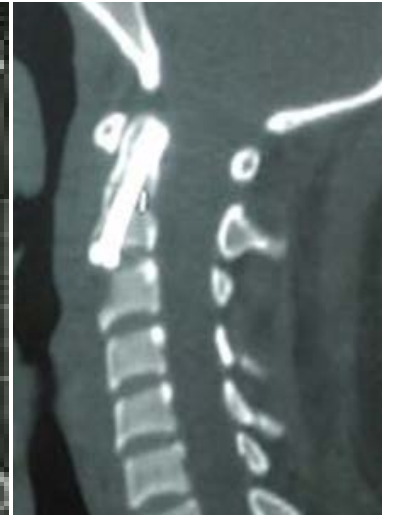

(b)

Figure 1. Sagittal CT cervical spine pre (a) and post-operative (b) of a patient with type II $\mathrm{b}$ odontoid fracture with adequate placement of odontoid screw.
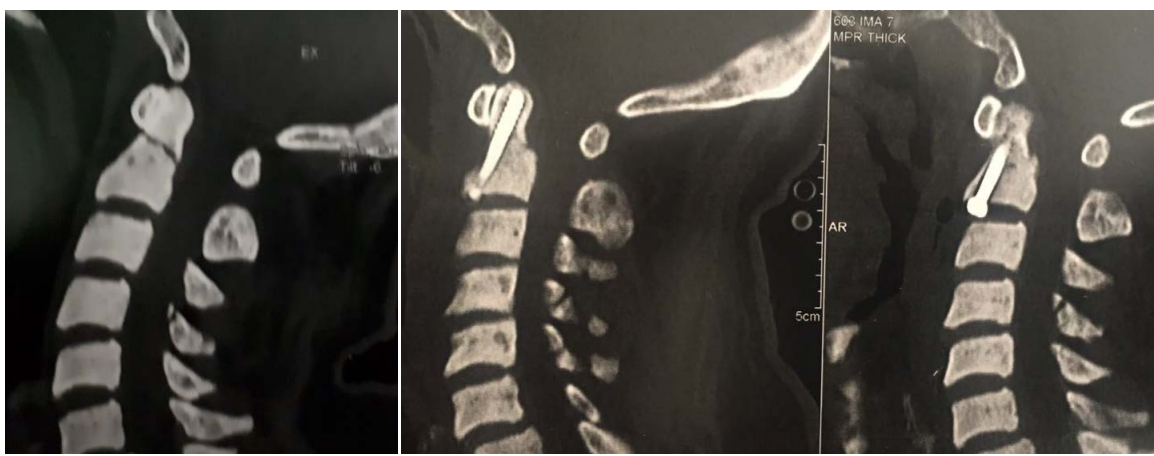

(a) 

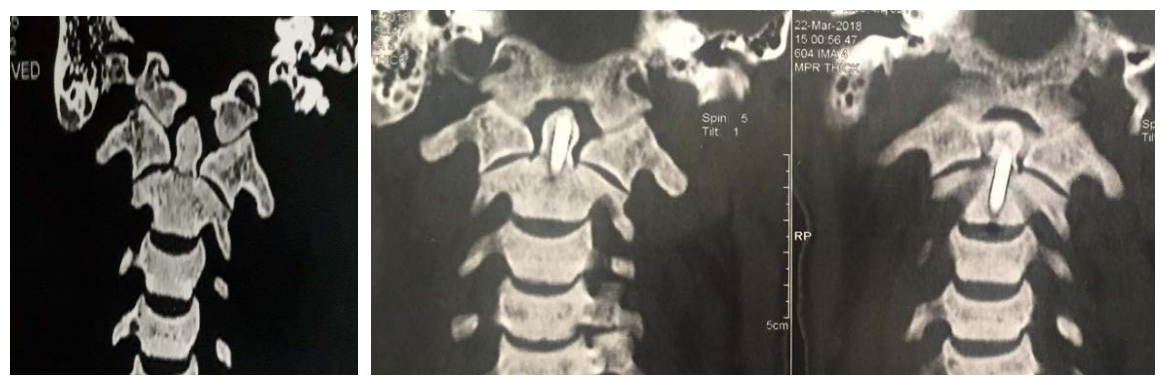

(b)

Figure 2. (a) Sagittal CT cervical spine pre and post operative; (b) Coronal CT cervical spine pre and post operative with adequate placement of odontoid screw.

CT cervical spine post-operative to confirm screw position, stability and serve as base line imaging for evaluating fusion on follow up visits.

We inserted single partially threated titanium screw with different sizes (lag screw) in 10 cases. Suction drain was removed on second day and broad-spectrum antibiotic was given for one week. Follow-up CT cervical spine was scheduled after 1.5, 3 and 6 months from surgery date.

Exclusion criteria included disrupted transverse ligament, anterior oblique fracture, associated Jefferson fractures, short neck, emphysematous chest and old fractures.

\section{Operative pitfalls and keys for increasing experience}

In our institute we have only the uni-planner fluoroscopy and this was difficult to start up experience in this type of surgery. So, we strictly followed the classic anatomical facts that made the use of uni-planner fluoroscopy helpful to achieve successful screw insertion.

*Tricks of positioning:

- Supine patient position over radiolucent table is mandatory. At this step we usually put suitable drape roll under inter-shoulder region trying to elevate base of the neck to avoid K-wire kinking during initial targeting of the midline.

- Roll of gauze should be placed in the mouth to have good open-mouth imaging view intra-operative as illustrated in Figure 3.

- We use skull traction in neutral position in all patients with $6 \mathrm{~kg}$ weight which was suitable for all patients to maintain midline checking and alignment of fracture line for easier screw purchases.

\section{*Tricks of exposure:}

- Transverse skin incision at level of C5-6 level within one of the natural neck creases, side of surgery will be left side for left handed surgeon and vice versa because he will use his dominant hand to hold the twist drill.

- Exposure C2-3 disc space and removal of only $5 \mathrm{~mm}$ from its anterior surface in the midline (entry point).

- The two longus colli will unit in the midline of anterior arch of $\mathrm{C} 1$ which is another midline check point. 


\section{*Tricks of screw purchase:}

- We used manual twist drill in all cases which need to be grasped with the dominant hand like pistol with the rotating arm up.

- Assuring midline with K-wire track should be continuously checked by changing fluoroscopy between AP (open mouth) and Lateral positions. And this should be done to avoid the surgeon tendency to mal direct the K-wire to the other side of surgery as illustrated in Figure 4.

- Kinked K-wire should be replaced once noticed as it may misdirect the screw.

- We used $34 \mathrm{~mm}$ screw length in all patients and the length of serrated part was adjusted to fit only in the fractured part of odontoid to prevent pull out and stabilize the fracture.

- Small part of under surface of C2 in the midline should be removed to hold the screw head after complete insertion.

\section{Results}

We operated 6 males (60\%) and four females (40\%) as illustrated in Figure 5 and age ranged from 22 years to 59 years with mean 37 years.

Two cases (20\%) were associated with general co-morbidities (diabetes and hypertension), only three cases were not associated with trauma related injuries (30\%) while seven patients associated with trauma related injuries (70\%).

Seven patients presented to our ER department after road traffic accident (70\%) while three patients fall from height (30\%) as demonstrated in Figure 6.

All patients complain of neck pain at time of presentation (100\%) while two of them associated with upper limb weakness due to cervical cord contusion. (20\%).

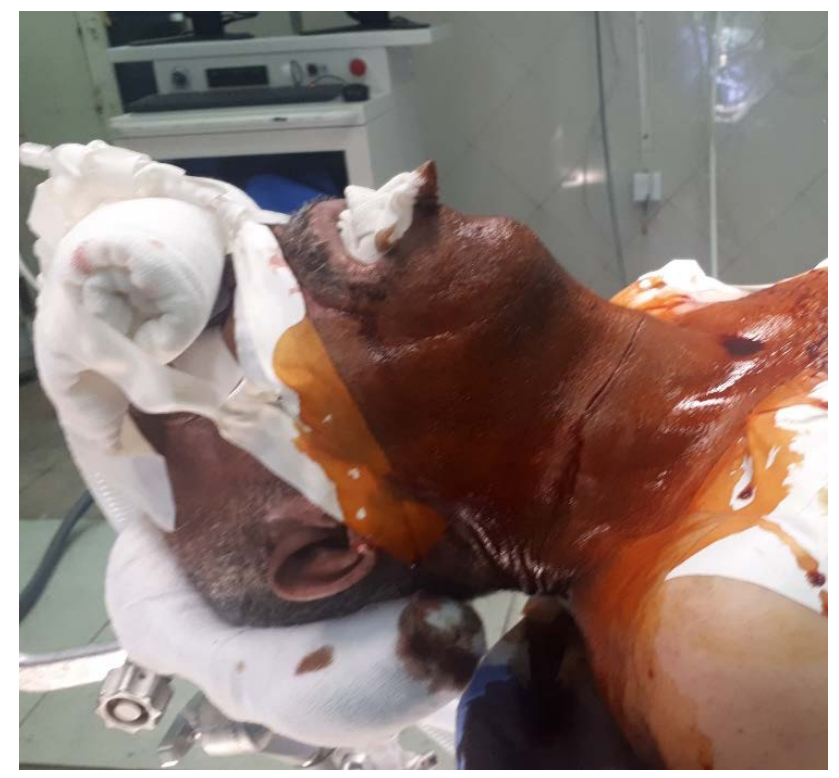

Figure 3. Intraoperative photo showing Supine positon of the patient with drape roll under inter-shoulder region trying to elevate base of the neck and a roll of gauze placed in the mouth to have good open-mouth imaging view. 


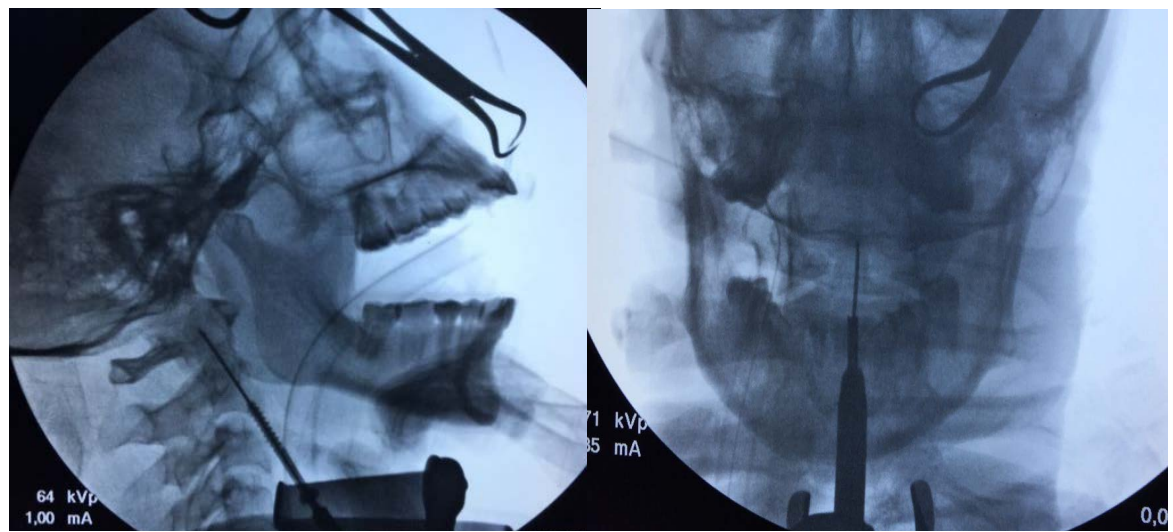

Figure 4. Intraoperative $\mathrm{X}$-ray photos showing $\mathrm{k}$ wire tracking into fractured odontoid process in both lateral and postero-anterior open mouth views.

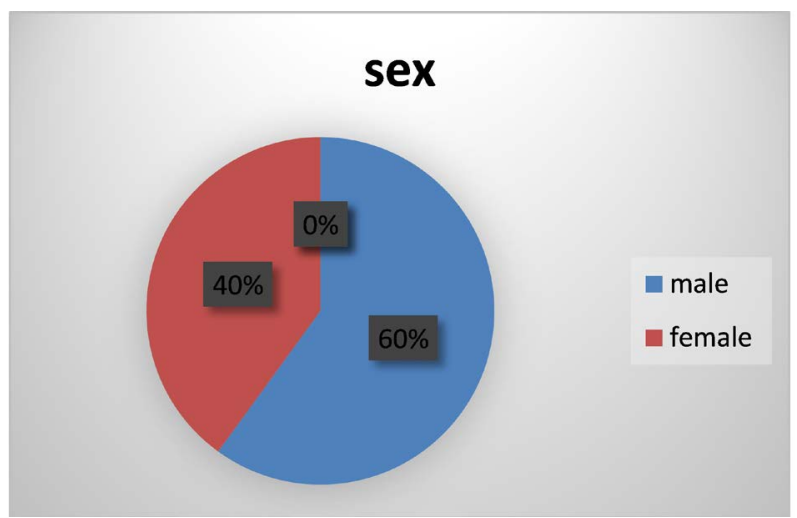

Figure 5. Sex distribution.

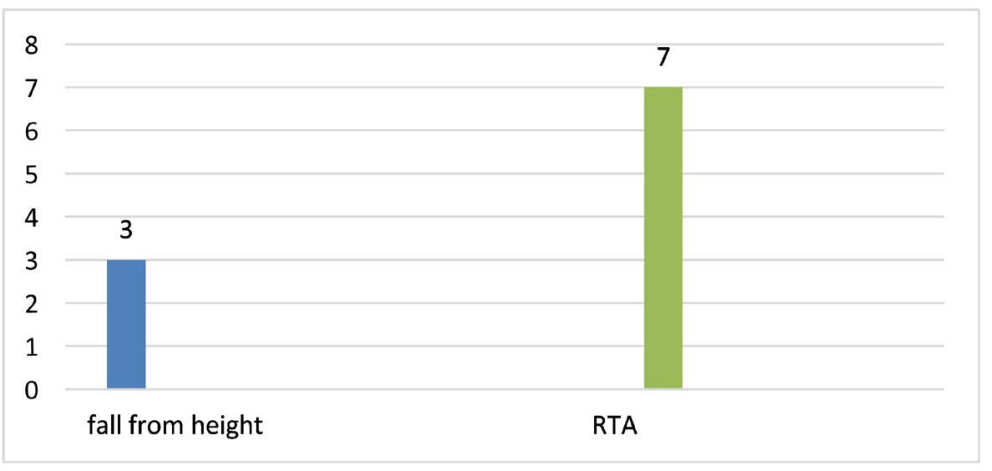

Figure 6. Mode of trauma (RTA: road traffic accident).

No intra-operative complications occurred apart from kinking of K-wire in two cases which necessitates replacement by new ones which require midline and track re-checking.

No post-operative complications related to the procedure or wound complications, seven patients (70\%) were discharged to home on third postoperative day with Philadelphia neck collar, two patients with weakness stayed in hospital one week on physiotherapy (20\%) and one patient was in ICU for three days post-operative due to associated lung contusion. three patients had post-operative 
dysphagia (30\%) which improved spontaneously over three weeks.

All post-operative CT cervical spine done on second post-operative day show stable reduced odontoid process. Follow up CT after 1.5 and 3 months show well alignment with good fusion with no signs of mal union or psudoarthrosis and patients were followed up for six months.

The two cases with upper limb weakness showed improved motor power over three months on regular physiotherapy.

\section{Discussion}

Odontoid process type II fractures eventually will need fixation. Some authors prefer to conserve by wearing halo vest [21] but this may not be suitable for many patients especially in young active working patients, more over fixation will enhance healing fusion and avoid mal-union or pseudo-arthrosis that may occur in conservative treatment [21].

Road traffic accident (RTA) is common in developing countries with higher possibility of trauma related spine fracturs including odontoid fractures. RTA represents about $70 \%$ of our cases compared to what was found by Sunil et al. where $60 \%$ of their cases had RTA [22]. and $80 \%$ of patients included in Wilson study presented after RTA [23].

The mean age for our patients is 37 years (compared to 35 years which is the mean age encountered in Sunil work) which is relatively young and usually active working persons and that was reflected on treatment options considering early return to work.

Odontoid screw fixation provides immediate stabilization with preservation of C1-2 motion and enhance fusion which is the ultimate goal of management [16].

The need to do odontoid screw fixation for this kind of patients plus the absence of newly introduced intra-operative tools like $\mathrm{O}$ arm and neuronavigation which facilitate surgery has make it more difficult to gain increasing experience in developing countries.

We did skull traction as routine step for all patients who were helpful in alignment of fracture line and this was confirmed by intra-operative fluoroscopy. Also, it facilitates the avoidance of neck manipulations required for fracture line alignment done by Sunil. We assured this step especially that no intra-operative electro-physiological monitoring is available in our institute.

One titanium lag screw was inserted in all cases and this was wise enough in starting up experience in addition, bone quality was fine as most patients where below 50 years with no history of bone quality affecting diseases. Sunil et al. [22] also inserted one screw in all cases, while Dailey et al. found that putting 2 screws enhance better fusion but their cases were older than 70 years [24]. And this may explain their need to assure fixation due to possible weak bone quality.

Moreover, there no clinical or biomechanical studies concluded any difference between inserting one or two screws in terms of healing rate, load bearing strength and neck rotation power [25] [26]. 
Uni-cortical screw purchasing was done in all cases and we did not notice any problem related to avoiding bi-cortical engagement including; screw back out, fracture and fusion slowing rate during follow up. Apfelbaum et al. [14] stated that bi-cortical screw purchasing is essential to achieve fracture healing. Also, he reported four cases of screw back out, one of them died from brain stem and cervical cord compression.

Our analysis for that difference may be related to different study population with subsequent pathological status that may affect bone quality and relatively short follow up period in our study (6 months).

Our cases did not show operative major complications including vascular, neural injury, oesophageal tear which are dangerous complications that may be encountered in anterior screw odontoid fixation [14].

Smith et al. reported that these patients are more liable to have post-operative airways problems including oedema, tracheostomy, pneumonia and ventilation [26] but fortunately none of our patient had developed any of these complications.

Dysphagia occurred in three of our patients post-operative which explained by retracting pharynx during operation and resolved over three weeks on throat soothing lozenges and anti-oedema pills. Dailey et al. reported that there is higher incidence of dysphagia post-operatively in elderly patients did anterior cervical surgery $35 \%$ of them require Ryle tube insertion and diet modification [24].

Our study limitations include the availability of intra-operative tools that may increase building up experience. Larger number study and longer follow up should be considered in future studies.

\section{Conclusion}

Odontoid screw fixation is a better option than conservative treatment in type II odontoid fracture especially in young actively working persons. Limited resources in developing countries shouldn't prevent starting up a cautious experience in this technique with the available equipments, concomitant with mandatory improvement of operation safety tools.

\section{Conflicts of Interest}

The authors declare no conflicts of interest regarding the publication of this paper.

\section{References}

[1] Dunn, M.E. and Seljeskog, E.L. (1986) Experience in the Management of Odontoid Process Injuries: An Analysis of 128 Cases. Neurosurgery, 18, 306-310. https://doi.org/10.1227/00006123-198603000-00008

[2] Scheyerer, M.J., Zimmermann, S.M., Simmen, H.P., Wanner, G.A. and Werner, C.M. (2013) Treatment Modality in Type II Odontoid Fractures Defines the Outcome in Elderly Patients. BMC Surgery, 13, 54.

https://doi.org/10.1186/1471-2482-13-54 
[3] Vasudevan, K., Grossberg, J.A., Spader, H.S., Torabi, R. and Oyelese, A.A. (2014) Age Increases the Risk of Immediate Postoperative Dysphagia and Pneumonia after Odontoid Screw Fixation. Clinical Neurology and Neurosurgery, 126, 185-189. https://doi.org/10.1016/j.clineuro.2014.09.006

[4] Vaccaro, A.R., Madigan, L. and Ehrler, D.M. (2000) Contemporary Management of Adult Cervical Odontoid Fractures. Orthopedics, 23, 1109-1113.

[5] Elgafy, H., Dvorak, M.F., Vaccaro, A.R. and Ebraheim, N. (2009) Treatment of Displaced Type II Odontoid Fractures in Elderly Patients. Am J Orthop, 38, 410-416.

[6] Anderson, L.D. and D'Alonzo, R.T. (1974) Fractures of the Odontoid Process of the Axis. The Journal of Bone \& Joint Surgery, 56, 1663-1674. https://doi.org/10.2106/00004623-197456080-00017

[7] Clark, C.R. and White III, A.A. (1985) Fractures of the Dens. A Multicenter Study. The Journal of Bone \& Joint Surgery, 67, 1340-1348. https://doi.org/10.2106/00004623-198567090-00006

[8] Müller, E.J., Schwinnen, I., Fischer, K., Wick, M. and Muhr, G. (2003) Nonrigid Immobilisation of Odontoid Fractures. European Spine Journal, 12, 522-525. https://doi.org/10.1007/s00586-003-0531-1

[9] Joaquim, A.F. and Patel, A.P. (2010) C1 and C2 Spine Trauma: Evaluation, Classification and Treatment. Contemporary Spine Surgery, 11, 1-7. https://doi.org/10.1097/01.CSS.0000369159.82865.84

[10] Joaquim, A.F. and Patel, A.P. (2010) Occipito Cervical Trauma: Evaluation, Classification and Treatment. Contemporary Spine Surgery, 11, -5.

[11] Mashhadinezhad, H., Samini, F., Mashhadinezhad, A. and Birjandinejad, A. (2012) Clinical Results of Surgical Management in Type II Odontoid Fracture: A Preliminary Report. Turkish Neurosurgery, 22, 583-587.

[12] Bohler, J. (1982) Anterior Stabilization for Acute Fractures and Non-Unions of the Dens. The Journal of Bone \& Joint Surgery, 64, 18-27. https://doi.org/10.2106/00004623-198264010-00004

[13] Dickman, C.A., Foley, K.T., Sonntag, V.K. and Smith, M.M. (1995) Cannulated Screws for Odontoid Screw Fixation and Atlantoaxial Transarticular Screw Fixation. Technical Note. Journal of Neurosurgery, 83, 1095-1100. https://doi.org/10.3171/jns.1995.83.6.1095

[14] Apfelbaum, R.I., Lonser, R.R., Veres, R. and Casey, A. (2000) Direct Anterior Screw Fixation for Recent and Remote Odontoid Fractures. Journal of Neurosurgery, 93, 227-236.

[15] Hénaux, P.L., Cueff, F., Diabira, S., Riffaud, L., Hamlat, A., et al. (2012) Anterior Screw Fixation of Type IIB Odontoid Fractures in Octogenarians. European Spine Journal, 21, 335-339. https://doi.org/10.1007/s00586-011-2044-7

[16] Rajasekaran, S., Kamath, V. and Avadhani, A. (2010) Odontoid Anterior Screw Fixation. European Spine Journal, 19, 339-340. https://doi.org/10.1007/s00586-010-1305-1

[17] Smith, G.W. and Robinson, R.A. (1958) The Treatment of Certain Cervical-Spine Disorders by Anterior Removal of the Intervertebral Disc and Interbody Fusion. The Journal of Bone and Joint Surgery, 40, 607-624.

[18] Jaiswal, A., Shetty, A.P. and Rajasekaran, S. (2007) Role of Intraoperative Iso-C Based Navigation in Challenging Spine Trauma. Indian Journal of Orthopaedics, 41, 312-317. https://doi.org/10.4103/0019-5413.36993

[19] Kantelhardt, S.R., Keric, N. and Giese, A. (2012) Management of C2 Fractures Us- 
ing Iso-C3D Guidance: A Single Institution's Experience. Acta Neurochirurgica, 154, 1781-1787. https://doi.org/10.1007/s00701-012-1443-9

[20] Wu, J.C., Wadhwa, R., Than, K., et al. (2014) Complication Avoidance and Management Using the O-arm for Odontoid Screw Fixation: Technical Note. Cureus, 6, e225. https://doi.org/10.7759/cureus.225

[21] Shilpakar, S., McLaughlin, M.R., Haid, R.W., et al. (2000) Management of Acute Odontoid Fractures: Operative Techniques and Complication Avoidance. Neurosurgical Focus, 8, e3.

[22] Munakomi, S., Tamrakar, K., Chaudhary, P.K., Bhattarai, B., et al. (2016) Anterior Single Odontoid Screw Placement for Type II Odontoid Fractures: Our Modified Surgical Technique and Initial Results in a Cohort Study of 15 Patients. F1000Research, 5, 1681. https://doi.org/10.12688/f1000research.9131.2

[23] Wilson, D.A., Fusco, D.J. and Theodore, N. (2011) Delayed Subarachnoid Hemorrhage Following Failed Odontoid Screw Fixation. Journal of Neurosurgery: Spine, 14, 715-718. https://doi.org/10.3171/2011.1.SPINE10561

[24] Dailey, A.T., Hart, D., Finn, M.A., Schmidt, M.H. and Apfelbaum, R.I. (2010) Anterior Fixation of Odontoid Fractures in an Elderly Population. Journal of Neurosurgery. Spine, 12, 1-8. https://doi.org/10.3171/2009.7.SPINE08589

[25] Jenkins, J.D., Coric, D. and Branch, C.L. (1998) A Clinical Comparison of One- and Two-Screw Odontoid Fixation. Journal of Neurosurgery, 89, 366-370. https://doi.org/10.3171/jns.1998.89.3.0366

[26] Smith, H.E., Vaccaro, A.R., Maltenfort, M., Albert, T.J., Hilibrand, A.S., Anderson, D.G., et al. (2008) Trends in Surgical Management for Type II Odontoid Fracture: 20 Years of Experience at a Regional Spinal Cord Injury Center. Orthopedics, 31, 650. 